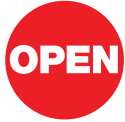

SUBJECT AREAS:

BIODIVERSITY

MICROBIAL ECOLOGY

COMMUNITY ECOLOGY

COMMUNITIES

Received

24 September 2012

Accepted

12 December 2012

Published

8 January 2013

Correspondence and requests for materials should be addressed to

A.M.S. (amsegura@ fcien.edu.uy)

\section{Competition Drives Clumpy Species Coexistence in Estuarine Phytoplankton}

\author{
A. M. Segura' ${ }^{1,2}$, C. Kruk ${ }^{2,3,4}$, D. Calliari ${ }^{1,2}$, F. García-Rodriguez' ${ }^{1}$ D. Conde ${ }^{2,3}$, C. E. Widdicombe ${ }^{5}$ \\ \& H. Fort ${ }^{6}$
}

'Universidad de la República, Facultad de Ciencias, Oceanography and Marine Ecology, Montevideo, Uruguay, ${ }^{2}$ Functional Ecology of Aquatic Systems, Universidad de la República, Uruguay, ${ }^{3}$ Universidad de la República, Facultad de Ciencias, Institute of Ecology and Environmental Sciences, Limnology, Montevideo, Uruguay, ${ }^{4}$ Institute of Biological Research Clemente Estable - MEC, Laboratory of Ethology, Ecology and Evolution, Montevideo, Uruguay, ${ }^{5}$ Plymouth Marine Laboratory, Prospect Place, West Hoe, Plymouth PL1 3DH, UK, `Universidad de la República, Physics institute, Complex Systems Group, Montevideo, Uruguay.

Understanding the mechanisms that maintain biodiversity is a fundamental problem in ecology. Competition is thought to reduce diversity, but hundreds of microbial aquatic primary producers species coexist and compete for a few essential resources (e.g., nutrients and light). Here, we show that resource competition is a plausible mechanism for explaining clumpy distribution on individual species volume (a proxy for the niche) of estuarine phytoplankton communities ranging from North America to South America and Europe, supporting the Emergent Neutrality hypothesis. Furthermore, such a clumpy distribution was also observed throughout the Holocene in diatoms from a sediment core. A Lotka-Volterra competition model predicted position in the niche axis and functional affiliation of dominant species within and among clumps. Results support the coexistence of functionally equivalent species in ecosystems and indicate that resource competition may be a key process to shape the size structure of estuarine phytoplankton, which in turn drives ecosystem functioning.

r he struggle for existence restricts the number of coexisting species to the number of limiting resources ${ }^{1}$. Recognition that hundreds of aquatic microbial producers (i.e., phytoplankton) compete for light and a few essential diluted nutrients led to the formulation of the paradox of the plankton ${ }^{2}$. Since Hutchinson's proposal, several niche-based mechanisms such as environmental fluctuation ${ }^{2}$, trophic ${ }^{3}$ or chaotic population dynamics ${ }^{4}$ were proposed to explain species diversity. Another view to explain species coexistence based on neutral-based mechanisms assumes that species populations are equivalent with regard to fitness ${ }^{5}$. This fitness equivalence was proposed for the phytoplankton of tropical oceans ${ }^{6}$, but the robustness of those findings was questioned $^{7}$. Two recent time-series analyses of coastal phytoplankton showed that a combination of neutral and niche-based mechanisms can indeed promote coexistence and also shape community size structure ${ }^{8,9}$, thus suggesting that competition is the main driving process. The Emergent Neutrality hypothesis ${ }^{10}$ proposes that competition for resources structures a community by selecting specific traits along a niche axis, but fitness of groups sharing the selected trait will be equivalent and thus subject to stochastic selection processes ${ }^{11}$. This hypothesis predicts that along a niche axis (i.e., individual volume) species biomass will clump within specific regions, while other regions will be mainly empty. However, empirical evidence is scarce ${ }^{9,12}$.

Body size is one of the most conspicuous properties of organisms ${ }^{13}$ subject to natural selection via sizedependent physiological rates, biological interaction and environmental forcing, which in turn defines specific fitness. Phytoplankton cell size range is unparalleled, with over nine orders of magnitude in volume ${ }^{14}$. Its sizestructure influences key processes such as the carbon flux to the deep ocean, the transference of energy towards higher trophic levels and the biogeochemistry of bioactive elements ${ }^{15}$. In turn, it is affected by climate and nutrient enrichment ${ }^{16}$. Thus, understanding the mechanisms that modulate phytoplankton size-structure and composition is crucial to comprehend the functioning of aquatic ecosystems in a global change scenario.

Assuming size is a good proxy for the niche $e^{11,13}$, we evaluate the hypothesis that resource competition along a niche axis is the main driver of phytoplankton community structure. To that end, we analyzed patterns in size and functional structure at ecological and paleoenvironmental time-scales using a multi-system long-term database and a Lotka-Volterra competition model ${ }^{9}$.

\section{Results}

Phytoplankton clumpy coexistence. Species and biovolume dominance of species from morphology-based functional groups V (flagellate organisms) and VI (diatoms) in estuaries were conspicuous. These groups 
accounted for on average $c a .91 \%$ of species richness and more than $99 \%$ of total community biovolume. A clumpy multimodal sizedistribution of phytoplankton, as suggested by entropy profiles and evaluated with DIP test $(\mathrm{P}<0.05)$, occurred in all three estuaries (Fig. 1). This is a remarkable fact given the differences in size, depth, and trophic status of these ecosystems (Supplementary Table S1 online). This clumpy pattern could be considered as the (quasi-) equilibrium state of the community, as the temporal scale involved (e.g., San Fransisco Bay and English Channel; ca. 10 years) represents on average more than 2000 generations for phytoplankton. This was readily confirmed by the observed clumpy size distribution of diatom species (Fig. 2) for the last $3000 \mathrm{yr}$ BP in Laguna Blanca. This pattern was conserved throughout the Holocene, although different diatom association zones (DAZ) were identified ${ }^{17}$. These zones are indicative of past salinity-regimes, and despite substitution in the dominant species under different DAZ, diatoms clumped in either medium- or large-sized ranges throughout the record (Fig. 2). The clumpy pattern was reproduced by the competition model (eqn. 2) which predicted not only the positions in the niche axis, but also the functional affiliation of the dominant species (Fig. 3).

Larger sizes in marine vs. freshwater environments. Empirical data showed that peaks and troughs shifted to larger sizes in the size spectrum in systems with a stronger marine influence (English Channel; Fig. 1) where the largest sizes of phytoplankton $\left(10^{6} \mu^{3}\right)$ dominated. Differently, in the inner Rio de la Plata estuary, dominant sizes were in the order of $10^{3} \mu \mathrm{m}^{3}$. Those results are in close agreement with higher average size of marine diatoms compared to freshwater species ${ }^{14}$ and dominance of middle-sized species in a coastal brackish lagoon ${ }^{9}$. Individual size of phytoplankton tends to decrease in evolutionary time-scales ${ }^{18}$. Alternatively, changes in the upper limits of the individual size in freshwater $v s$. marine organisms might result from different limiting nutrient (phosphorus vs. nitrogen in freshwater and coastal marine environments, respectively) and frequency of nutrient pulses ${ }^{14}$. Once adjusted for the maximum attainable size at each system, the model adequately reproduced the observed clumpy size structure (Fig. 3), thus supporting the hypothesis that competition is the main ecological force shaping the observed size patterns in estuarine phytoplankton communities.

\section{Discussion}

The observed clumpy size distribution of biomass, entropy profiles and abiotic differences among systems support Emergent Neutrality hypothesis as a plausible mechanism in shaping multimodal community structure ${ }^{8,9,11,12}$. Furthermore, the competition model, whose parameter values were chosen from independent literature-reviewed values and measured quantities, was able to reproduce the clumpy patterns and predict functional affiliation of dominant species along a niche axis.

Present results do not support alternative explanations of community structure and species coexistence like pure Neutrality ${ }^{5}$ or the High Dimensional hypothesis $(\mathrm{HDH})^{9}$. Neither of these mechanisms predict clumpy distributions of traits in the niche axis as observed here. For instance, hypotheses regarding pure neutrality, predict a uniform trait distribution of species in the niche axis ${ }^{5,9}$. Even if there are other relevant niche dimensions (e.g., silica dependence, resistant structures or temporal niche partitioning), as proposed by $\mathrm{HDH}$, the associated mechanisms are not expected to generate any particular trait distribution?. Processes such as temporal niche partitioning, as suggested in the Margalef's Mandala ${ }^{20,15}$, can operate along with
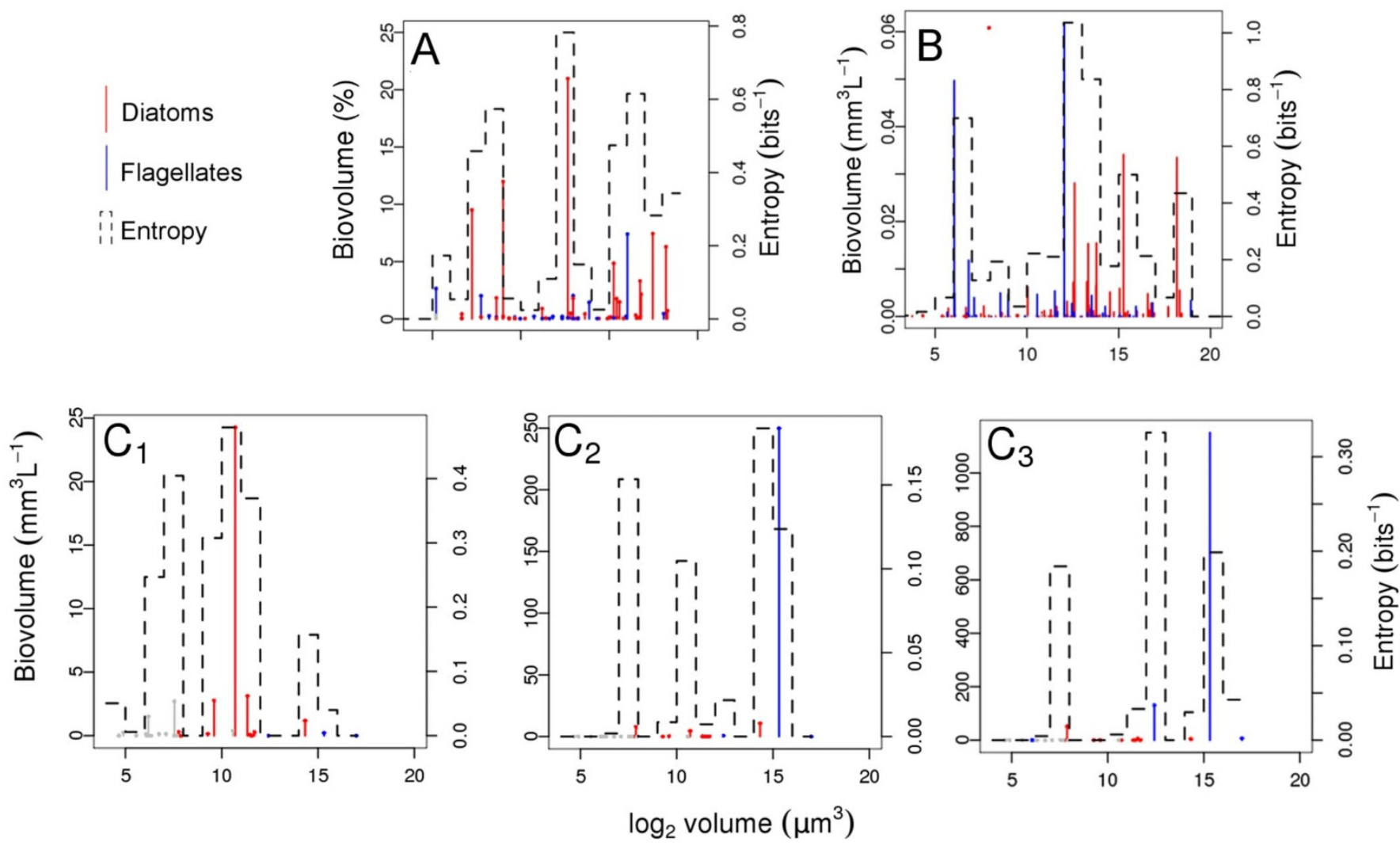

Figure 1 Coastal phytoplankton clumpy size structure. Black dashed lines indicate diversity in each size bin as defined in the text. Blue and red vertical lines represent individual species volume of morphology-based functional group V (flagellates) and VI (e.g., diatoms), respectively and grey lines represent group IV (e.g., Ankistrodesmus sp.). A, San Francisco Bay (USA); B, English Channel (UK); C1-3, Rio de la Plata (Uruguay) inner, middle and outer sections, respectively. 


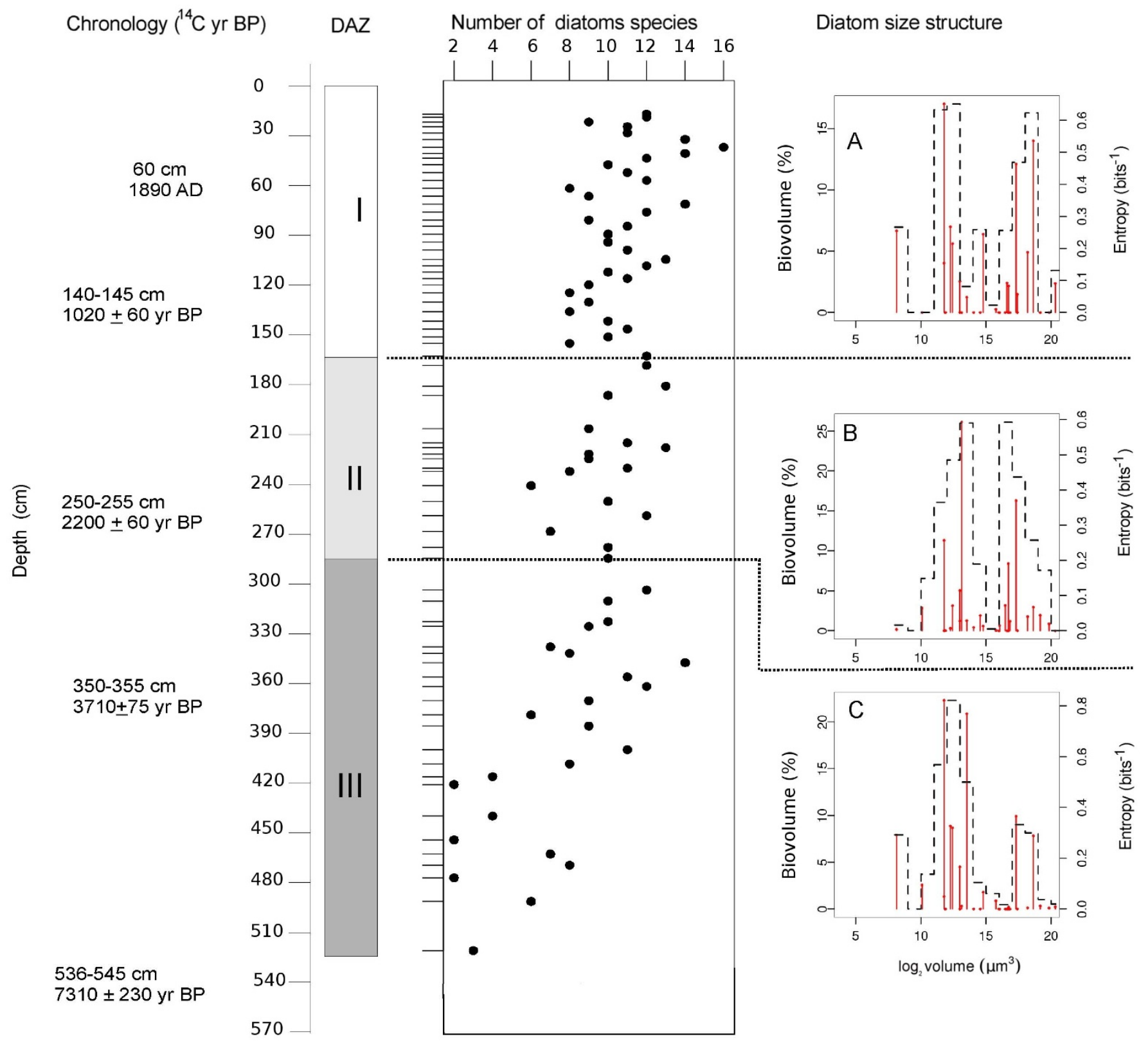

Figure $2 \mid$ Paleoecological data from Laguna Blanca, Uruguay showing the number of coexisting diatom species. Diatom association zones (DAZ), indicative of changes in paleosalinity levels, DAZ III marine-brackish, DAZ II brackish-freshwater, DAZ I freshwater. Diatom clumpy size structure within A, DAZ I; B, DAZ II; C, DAZ III.

Emergent Neutrality mechanism to generate the observed pattern of long-term coexistence among flagellates and diatoms in estuarine waters $^{15}$. Thus, Emergent Neutrality does not rule out either mixing conditions as a factor influencing diatoms dominance, or water stability as a factor promoting flagellates dominance. It also envisages paradoxical examples where flagellates dominate over diatoms independently of nutrient concentration or light intensity, only depending on initial conditions $\mathrm{s}^{21,22}$.

An alternative mechanism that predicts clumpy patterns caused by the distribution and fractionation of resources is Holling's Textural hypothesis ${ }^{19}$. However, in a first approximation the Textural Hypothesis does not appear as a likely explanation for the observed pattern. Similarities in the clumpy structure were found for distant ecosystems in freshwater and marine realms, with different abiotic constraints and widely different sizes. Heterogeneity in the physical and chemical structure of aquatic systems is linked to the range of scales of operating processes, which in turn is associated with the spatial scale of the ecosystem ${ }^{23}$. For instance, patterns of water circulation - a prime factor describing the physical structure of aquatic ecosystems - encompass a range of scales from the size of the basin that contains the water body to the $\mathrm{mm}-\mathrm{cm}$ Kolmogoroff scale where mechanical energy is dissipated as heat ${ }^{23}$. Chemical and biological patterns and processes scale to such variability. Within that context, it is unlikely that similar clumpy patterns in the structure of biological communities could be environmentally-driven (from a textural standpoint) as these arise in such dissimilar physical contexts as small lagoons, large-scale estuaries and coastal seas. These similarities in the size distribution of microbial communities point towards more general physiological and interacting mechanisms for which Emergent Neutrality appears as a more parsimonious explanation.

Another piece of evidence supporting the Emergent Neutrality hypothesis is that the number of clumps observed in the English Channel, Rio de la Plata and San Francisco Bay was in agreement 


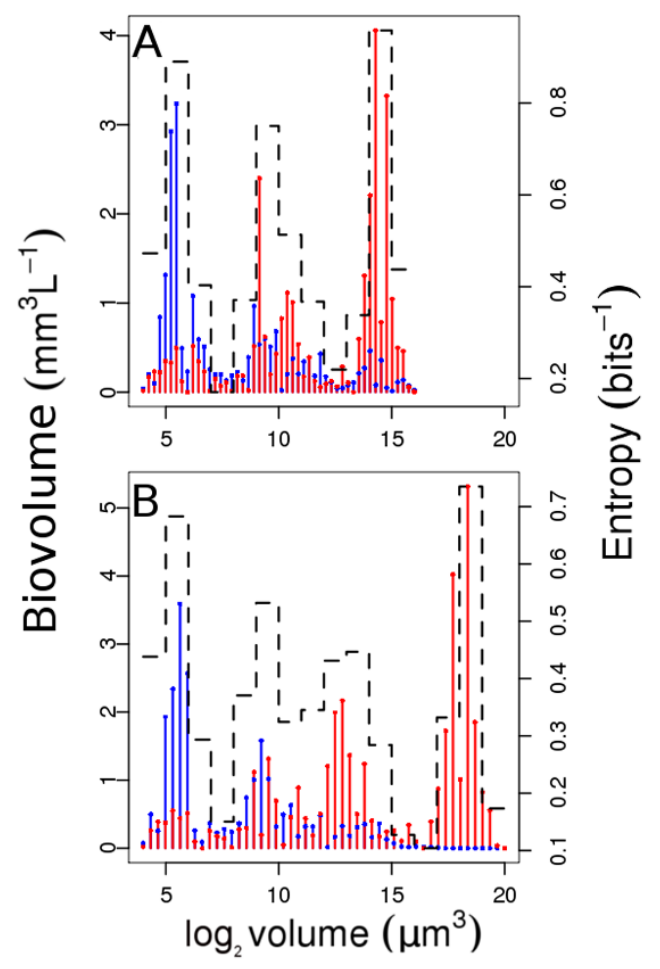

Figure $3 \mid$ Modeled phytoplankton size structure and species coexistence. $A$ and $B$ represent simulations with maximum phytoplankton volume similar to Rio de la Plata and English Channel observed maxima $\left(10^{4}\right.$ and $10^{6}$ ) respectively. Black dashed lines represent average entropy calculated over 5000 simulations. Blue and red lines represent species from morphology-based functional group V and VI respectively.

with theoretical expectations. It was analytically derived that for a simplified case (the same niche width $(\sigma)$ and carrying capacity for all species, together with a circular or periodic niche axis) the number of clumps coincides with the number of peaks of the dominant eigenvector of the community matrix ${ }^{24}$. This relationship is robust to changes in niche width and can be expected to hold under realistic conditions ${ }^{25}$. Thus, in the cases under study, and based on an empirical relationship of $\sigma$ and niche width (individual volume) the expected number of clumps in estuarine communities is $C=3$ in Rio de la Plata and San Francisco Bay, and $C=4$ in the English Channel.

An additional question to address is how ecologically-equivalent species arise in different estuarine-coastal ecosystems. The paleontological record suggests that the appearance of new species frequently coincides with major climatic events that disrupt the integrity of ecological systems ${ }^{26}$. We interpret that restrictions for establishment and invasion do not affect equivalent species that arrive during periods of community disruption, as they do for species entering long-standing systems. The dominant functional groups in the estuarine domain correspond to two of the three groups of marine eukaryotic phytoplankton that commonly dominate the modern oceans (diatoms and flagellates). Such groups belong to the "red lineage" sensu Falkoswki ${ }^{15}$. Species from this lineage evolved together relatively recently in Earth's history during the End-Permian mass extinction. This event marked a major transition in oceanic ecosystem structure, and was presumably a period of ecosystem instability and reconstitution ${ }^{15}$. At ecological time scales, estuarine environmental variability, such as floods or salinity changes, promotes the onset of equivalent phytoplankton species from different morphology-based functional groups when the community is "disrupted". This environmental variability differs from lake or oceanic systems, where fundamental structuring mechanisms (e.g., resource competition) are expected to hold. However, relative stability in environmental conditions would not allow equivalent species to arise as; to our knowledge there are no available examples of clumpy size-structure for oceanic or freshwater primary producers.

The coexistence analysis of phytoplankton species in changing estuarine waters also helps to understand basic questions about macroevolutionary patterns. For instance, what is the significance in eco-evolutionary terms of convergence to specific individual sizes? Here, we show that despite differences in physiological strategies, that is, the relationship between size, growth and sinking rates for particular morphology-based functional groups, species evolved towards a similar volume in coastal zones as has been shown previously ${ }^{9,20}$. Thus coexistence of species from different functional groups is expected at particular size ranges where fitness differences are small (Fig. 1 and 3) which in turn shapes community size structure.

In summary, we showed Emergent Neutrality as a plausible mechanism promoting species coexistence and shaping community size structure in estuarine phytoplankton. Both anthropogenic impacts on nutrient fluxes to coastal areas and increases in water residence time are likely to modify phytoplankton species composition, size spectra, and ecosystem functioning.

\section{Methods}

Phytoplankton size-abundance distribution data. We compiled a database of our own and published data series of $c a .10$ years, composed of weekly to seasonal observations of individual size and biomass of phytoplankton species. It encompassed information from temperate and subtropical estuaries of both hemispheres. The data set comprised $>300$ species from large estuaries (San Francisco Bay- EEUU ${ }^{21}$; Rio de la Plata-Uruguay ${ }^{27}$ ) and a coastal region (L4 Plymouth station; English Channel $\left.\mathrm{UK}^{28}\right)$. The abundance and individual volume data were obtained from the following sources: average of decadal (1992-2001) seasonal sampling along the full salinity gradient of San Francisco Bay (Table 1 in Cloern \& Dufford) ${ }^{21}$; a spatially explicit spring snapshot design covering the full salinity gradient in Rio de la Plata in 2005 (Table 2 in Calliari et al) ${ }^{27}$ and data collected in the Western English Channel ${ }^{28}$ (http:// www.westernchannelobservatory.org.uk/14/Phytoplankton), 10 nautical miles off the coast of Plymouth $\left(50^{\circ} 15^{\prime} \mathrm{N}, 4^{\circ} 13^{\prime} \mathrm{W}\right)$, at the L4 station (1992-2003). This is an extensive data set, consisting of weekly sampling of phytoplankton abundance and their corresponding biomasses ${ }^{28}$. Detailed explanation of sampling design and counting methodologies can be found in the cited references.

Paleoecological data. To evaluate long-term temporal patterns in size structure, we analyzed paleoecological data of Laguna Blanca, a coastal lagoon in SE Uruguay, whose community record extends to $c a$. $5000 \mathrm{yr}$ BP. In the paleoecological data, we analyzed diatom species, a highly relevant class in coastal phytoplankton ${ }^{15}$, as they are well preserved in the fossil record. A $545 \mathrm{~cm}$-long core was taken in the deepest zone of Laguna Blanca-Uruguay in May 2000 with the aid of a 5-cm-diameter piston corer. After retrieval, the core was immediately sealed and kept in the dark at $4{ }^{\circ} \mathrm{C}$ prior to laboratory analysis. Sediments were dated by conventional and AMS ${ }^{14} \mathrm{C}$ on bulk sedimentary organic matter ${ }^{29}$. Age is expressed in conventional ${ }^{14} \mathrm{C} \mathrm{yr} \mathrm{BP}$, corrected by isotopic fractionation by normalizing $\delta^{13} \mathrm{C}$ values to $-25 \%$. Samples for diatom counting and identification were treated with $35 \% \mathrm{HCl}$ for 24 h to eliminate carbonates, and then rinsed four times with distilled water. Next, $10 \mathrm{ml}$ of $30 \% \mathrm{H}_{2} \mathrm{O}_{2}$ were added to eliminate organic matter, and then the samples were boiled for four hours and rinsed five times with distilled water. Permanent slides were mounted in Naphrax (R) for counting and identification. A minimum of 400 valves was counted at $1250 \times$ magnification in each sample. Species were identified according to published literature ${ }^{31-37}$. Diatom valves were measured at 600 and $1000 \times$ magnification using an optical microscope. Measurements were collated for each species with the maximum and minimum dimensions available in the literature ${ }^{30-39}$ In all cases our diatom dimensions were consistent with published literature.

In order to estimate individual volume from valve maximum linear dimension, we calculated the log-log relationship of valve maximum length to individual volume (Supplementary Fig. S1 online) by an ordinary least squares regression using published values of diatoms from the Baltic sea ${ }^{40}$. Linear regression $\left(\log _{2}\right.$ (volume) $=1.85$ $+2.43 \log _{2}$ (valve dimension); $\left.\mathrm{N}=596\right)$ was highly significant $(\mathrm{p}<0.01)$ and explained $92 \%$ of variance (Supplementary Fig. S1 online). Further details of sampling procedures can be found elsewhere ${ }^{17,29}$.

Morphology-based functional groups. Phytoplankton in modern and paleoecological samples were identified and classified to species level, measured by optical microscopy and classified into morphology-based functional groups (MBFG) as defined by Kruk et al. ${ }^{41}$. Significant differences in growth rate, sinking rates, demographic parameters and competitive ability have been shown for species of these groups $^{9,41}$. For each species of a given MBFG and size, we estimated growth and 
sinking rates from previously estimated allometric relationships ${ }^{9}$. Within each MBFG, individual phytoplankton volume was used as a proxy for the niche and species coexistence which was evaluated by means of entropy (see below) ${ }^{9,42}$.

Biovolume multimodality. We evaluated if the distribution of biovolume was multimodal by means of the DIP test ${ }^{42}$. This test measures multimodality by the maximum difference, over all sample points, between the empirical distribution function and the unimodal distribution function that minimizes that maximum difference.

Entropy calculation. Individual volume $\left(\log _{2}\right)$ was used as our central niche axis Results remained consistent when other bases were used (data not shown). To provide a quantitative framework for the clumping to favorable niches, we used the Shannon-Wiener index or entropy $(S)$. This index has been used to recognize aggregated species distribution in niche axes ${ }^{9,42}$ and is defined by

$$
S=-\sum_{1}^{n} p_{i} \log _{2} p_{i}
$$

where $p_{i}$ is the fraction of biovolume of species $i$ in the community of $n$ species. For each community, the niche axis was divided into equally spaced segments of one unit of $\log _{2}$ volume, because they exhibit more clearly the structure of clumps and gaps. For each segment, $S$ was calculated and represented its species diversity. Clumps were defined as modes in species diversity bracketed by segments of low species diversity.

Competition model. We used a Lotka-Volterra competition model in the niche axis $^{9,11,43}$ defined for $n$ species as,

$$
\frac{d N_{i}}{d t}=N_{i} \mu_{i} \frac{\left[K_{i}-\sum_{1}^{n}\left(\alpha_{i j} N_{j}\right)\right]}{K_{i}} \quad i=1: n
$$

where $N_{i}$ is the biomass, $\mu_{\mathrm{i}}$ is the maximum growth rate and $K_{i}$ is the carrying capacity of species $i$. The sum term represents the effect of competition of all species on species $i$. The model is similar to that used by Scheffer \& Van Ness ${ }^{11}$ but model parameter values were estimated from measured quantities. Phytoplankton physiological rates (i.e., growth, nutrient half saturation) and loss terms (i.e., sinking rate and grazing mortality) were gathered from the literature and scaled to morphological traits ${ }^{9}$. Regression models between individual volume and physiological rates and loss terms were estimated for each estuarine morphology-based functional group (MBFG; Group V; Flagellated organisms and Group VI; diatoms $)^{41}$ as in Segura et al. ${ }^{9}$. For each model species, characterized here by its individual volume and MBFG affiliation, a carrying capacity was estimated based on a well known resource competition model (see supplementary Methods section). Competition coefficients $\left(\alpha_{i j}\right)$ were estimated as the probability of overlap between species individual volumes ${ }^{9,11,43}$. The rationale is that species which are far apart in the niche axis (volume) will interact less than those that are closer, and that species with narrower niches will compete less than those with wider niches. Fifty competing species from each of the MBFG represented in estuarine systems were assigned to equally spaced positions on the niche axis. We set two scenarios with maximum individual volumes equal to observed phytoplankton maxima as $10^{4}$ and $10^{6}$ to explore its effect on community structure. MLVC model simulations where run using the estimated parameters $(\alpha, K$ and $\mu)$ for each species. In each scenario, 5000 simulations under different environmental conditions (flushing and resuspension) were performed starting with low random initial species biovolume $\left(N_{0}=\right.$ rand $\left.[0,1]\right)$. Species from both MBFG were seeded uniformly spaced along the whole volume axis. Results remained unaffected if species were placed at random in the axis (results not shown). Species position, biovolume and MBFG affiliation after 50 days were registered. Finally, average biovolume and entropy were estimated for the 5000 simulations. Detailed description of model rationale can be found in the Supplementary Methods section.

1. Gause, G. F. The Struggle for Existence (Williams \& Wilkins, Reprinted 1964 by Hafner, New York, 1934).

2. Hutchinson, G. E. The paradox of plankton. Am. Nat. 882, 137-145 (1961).

3. Benincà, E. et al. Chaos in a long-term experiment with a plankton community. Nature 451, 822-825 (2008).

4. Huisman, J., Johansson, A., Folmer, E. \& Weissing, F. Towards a solution of the plankton paradox: the importance of physiology and life history. Ecol. Lett. 4, 408-411 (2001).

5. Hubbell, S. P. The Unified Neutral Theory of Biodiversity and Biogeography (Princeton University Press, Princeton, 2001).

6. Barton, A. D., Dutkiewicz, S., Flierl, G., Bragg, J. \& Follows, M. J. Patterns of Diversity in Marine Phytoplankton. Science 327, 1509-1511 (2010).

7. Huisman, J. Comment on "Patterns of Diversity in Marine Phytoplankton" Science 329, 512 (2010).

8. Vergnon, R., Dulvy, N. K. \& Freckleton, R. P. Niches versus neutrality: uncovering the drivers of diversity in a species-rich community. Ecol. Lett. 12, 1079-1090 (2009).

9. Segura, A. M. et al. Emergent neutrality drives phytoplankton species coexistence. Proc. Royal Soc. B 278, 2355-2361 (2011).

10. Holt, R. D. Emergent neutrality. Trends Ecol. Evol. 21, 531-533 (2006).
11. Scheffer, M. \& van Nes, H. E. Self-organized similarity, the evolutionary emergence of groups of similar species. Proc. Natl. Acad. Sci. USA 103, 6230-6235 (2006).

12. Vergnon, R., Van Nes, E. H. \& Scheffer, M. Emergent neutrality leads to multimodal species abundance distributions. Nature comm. 3, (2012).

13. Woodward, G. et al. Body Size in Ecological Networks. Trends Ecol. Evol. 20, 402-409 (2005).

14. Litchman, E., Klausmeier, C. A. \& Yoshiyama, K. Contrasting size evolution in marine and freshwater diatoms. Proc Natl. Acad. Sci. USA 106, 2665-2670 (2009)

15. Falkowski, P. G. et al. The evolution of modern eukaryotic phytoplankton. Science 305, 354-360 (2004).

16. Finkel, Z. V. et al. A universal driver of macroevolutionary change in the size of marine phytoplankton over the Cenozoic. Proc. Natl. Acad. Sci. USA 104, 20416-20420 (2007).

17. García-Rodríguez, F. et al. Holocene trophic state changes in relation to sea level variation in Lake Blanca, SE Uruguay. J. Paleolimnology 31, 99-115 (2004).

18. Jiang, L., Schofield, O. M. E. \& Falkowski, P. G. Adaptive Evolution of Phytoplankton Cell Size. Am. Nat. 166, 496-505 (2005).

19. Holling, C. S. Cross-Scale Morphology, Geometry, and Dynamics of Ecosystems. Ecol. Monog. 62, 447-502 (1992).

20. Margalef, R. Life-forms of phytoplankton as survival alternatives in an unstable environment. Oceanologica Acta 1, 493-509 (1978).

21. Cloern, J. E. \& Dufford, R. Phytoplankton community ecology: principles applied in San Francisco Bay. Mar. Ecol. Prog. Ser. 285, 11-28 (2005).

22. Kremp, A., Taminen, T. \& Spilling, K. Dinoflagellate bloom formation in natural assemblages with diatoms: nutrient competition and growth strategies in Baltic spring phytoplankton. Aq. Microbial Ecol. 50, 181-196 (2008).

23. Mann, K. H. \& Lazier, J. R. N. Dynamics Of Marine Ecosystems (Blackwell Publisher - USA, 2006).

24. Graham, R. W. \& Group, F. W. Spatial Response of Mammals to Late Quaternary Environmental Fluctuations. Science 272, 1601-1606 (1996).

25. Fort, H., van Nes, E. H. \& Scheffer, M. The paradox of the clumps mathematically explained. Theoretical Ecology 2, 171 (2009).

26. Fort, H., van Nes, H. E. \& Scheffer, M. The Clumping Transition in Niche Competition: a Robust Critical Phenomenon. J Stat. Mech. May, 1-16 (2010)

27. Calliari, D., Gómez, M. \& Gómez, N. Biomass and composition of the phytoplankton in the Río de la Plata estuary: large scale distribution and relationship with environmental variables during a Spring cruise. Cont. Shelf Res. 25, 197-210 (2005).

28. Widdicombe, C. E., Eloire, D., Harbour, D., Harris, R. P. \& Somerfield, P. J. Long term phytoplankton community dynamics in the Western English Channel. J. Plankt. Res. 32, 643-655 (2010).

29. García-Rodríguez, F. et al. Paleolimnological assessment of human impacts in Lake Blanca, SE Uruguay. J. Paleolimnology 28, 457-468 (2002).

30. Lange-Bertalot, H. Diatoms of Europe (ed. A. R. G) (Gantner Verlag, Ruggell, 2001).

31. Witkowski, A., Lange-Bertalot, H. \& Metzeltin, D. in Iconographia Diatomologica (ed. Lange-Bertalot, H.) 925 (Koningstein, 2000).

32. Rumrich, U., Lange-Bertalot, H. \& Rumrich, M. in Iconographia Diatomologica (ed. Lange-Bertalot, H.) 673 (Koningstein, 2000).

33. Metzeltin, D. \& Lange-Bertalot, H. in Iconographia Diatomologica (ed. LangeBertalot, H.) 695 (Koningstein, 1998).

34. Krammer, K. in Diatoms of Europe (ed. Lange-Bertalot, H.) 702 (Ruggell, 2000)

35. Krammer, K. \& Lange-Bertalot, H. Bacillariophyceae 3. Teil: Centrales, Fragilariaceae, Eunotiaceae (G. Fischer Verlag, Stuttgart, Jena, 1991).

36. Krammer, K. \& Lange-Bertalot, H. Bacillariophyceae 1. Teil: Bacillariaceae, Epithemiaceae, Surirellaceae (G. Fisher, Stuttgart, Jena, 1988).

37. Krammer, K. \& Lange-Bertalot, H. Bacillariophyceae 1. Teil: Naviculaceae (G. Fisher, Stuttgart, Jena, 1986).

38. Metzeltin, D., Lange-Bertalot, H. \& García-Rodríguez, F. Diatoms of Uruguay Taxonomy, Biogeography, Diversity (ed. Lange-Bertalot, H.) (Gantner Verlag, distributed by Koeltz Scientific Books, Koenigstein, 2005).

39. Metzeltin, D. \& García-Rodríguez, F. Las diatomeas uruguayas (DIRAC, Montevideo, 2003)

40. Olenina, I. et al. Biovolumes and size-classes of phytoplankton in the Baltic Sea (2006).

41. Kruk, C. et al. A morphological classification capturing functional variation in phytoplankton. Fresh. Biology 55, 614-627 (2010).

42. Hartigan, J. A. \& Hartigan, P. M. The DIP test of unimodality. The annals stat. 13, 70-84 (1985)

43. May, R. M. Stability and complexity in model ecosystems (Princeton University, London, 1973).

\section{Acknowledgements}

We would like to thank CSIC (I+D 1037), ANII and PEDECIBA for partial funding of this work. AS is grateful to A. Mou for inspiring ideas and discussion and S. Ciavatta for statistical insight on multimodal testing. We also thank an anonymous reviewer whose comments helped to improve the discussion on the mechanisms of species coexistence. We thank the Plymouth Marine Laboratory, UK for making the station L4 phytoplankton 
time-series data available to us and the US Geological Survey for water quality data on San Francisco Bay (http://sfbay.wr.usgs.gov/access/wqdata).

\section{Author contributions}

A.S., D.Ca. and H.F. designed this research; D.Ca., C.K., D.Co., F-G.R. and C.W. generated phytoplankton data; A.S. ran the analyses, model simulations and wrote the manuscript. H.F. provided analytical tools and technical support in modeling and all authors contributed to writing and revising the manuscript.

\section{Additional information}

Supplementary information accompanies this paper at http://www.nature.com/ scientificreports

Competing financial interests: The authors declare no competing financial interests. License: This work is licensed under a Creative Commons

Attribution-NonCommercial-NoDerivs 3.0 Unported License. To view a copy of this license, visit http://creativecommons.org/licenses/by-nc-nd/3.0/

How to cite this article: Segura, A.M. et al. Competition Drives Clumpy Species Coexistence in Estuarine Phytoplankton. Sci. Rep. 3, 1037; DOI:10.1038/srep01037 (2013). 